\title{
Influence of regional conditions (ethnic, climatic, etc.) of Georgia on the selection methodology and sports orientation
}

\section{Tristan Gulbiani, Professor, Merab Maisuradze, Assistant Professor, Merab Metreveli, Assistan Professor}

\section{Tbilisi, Georgia, Georgian state teaching University of physical education and sport}

\section{Introduction}

Currently, an organizational and methodological system for selecting children and adolescents for sports is being developed. Control standards are proposed in certain sports that destroy the age characteristics of a growing organism and are intended to serve as a reference point for assessing the prospects of young athletes. it is natural that the program materials are based on the average results of the measured results and do not take into account specific regional, national, geographical, social and other features.

The existing individual differences in the biological development of novice athletes significantly complicate the task of children with suitable constitutional, functional and motor data for sports. This is all the more significant for regions with complicated climatic and geographical conditions, such as the Republic of Georgia.

When describing the climate, information about air temperature and humidity, wind speed, atmospheric pressure, and the ambient temperature, which is played by the sun, sky, and soil, is of crucial importance.

From the point of view of adaptation to climatic conditions, differences in body type between different populations are important. As you move from a moderate to a hot climate, the ratio of body weight to surface area decreases. It should be noted that the dependence of the size and shape of the body on the average temperature is explained by up to $50-60 \%$ of the inter-population variability. It depends on the nature of the physique and other factors, primarily on the mobility of the population. The elongated shape of the body prevails in people in hot climates. At the same time, a relatively large length per unit of weight is usually associated with a delay in the development of the skeleton of General physical maturation. Life in mountain conditions is a complex of environmental features associated with low barometric pressure( i.e. low oxygen and carbohydrate dioxide content in the inhaled air), low humidity and low temperature. In addition, in these areas, the soil is difficult to cultivate and requires considerable physical effort.

\section{Results}

The rate of change in longitudinal body size and proportion reveals clear geographical differences. On the European mainland allocate the South East region with increased brachymorphic, Western General aspect, North-West-with strengthening of brahmanya. P. K. Kvisinia studied the direction and degree of morphological differences between the 
population of the coastal and foothill zones of Georgia. The geographical conditions of Georgia, which represent chains of high mountain ranges that protect from cold winds from the North and the presence of a warm Black sea, have created a subtropical climate that creates favorable conditions for life. As you move away from the sea and climb to the mountains, the composition of the soil and water, flora and fauna, economic way of life, and diet change.

It is shown that the coastal zone has a muscular body type of $41.9 \%$, and the foothill zone has $34.5 \%$. Absolute differences between the extreme values of body size in adult men are 3 $\mathrm{cm}$ in length, more than $9 \mathrm{~kg}$ in weight, and $2 \mathrm{~cm}$ in chest circumference.

Compared with teenagers in other European countries, the number of muscle - type representatives among 12-year-old boys in Georgia is about twice as large. It was also found that indicators of muscle strength differ significantly between peers living in different regions. For example, the average result of hand dynamometry in boys in the southern zones was $8.6 \mathrm{~kg}$, in the Central regions of Europe - almost $16 \mathrm{~kg}$, respectively, in 15-year-olds-35$50 \mathrm{~kg}$. The same trend is observed in the long jump from a place. Therefore, generally accepted standards need to be adjusted to meet local conditions.

N. N. Miklashevskaya and her co-authors conducted a comparative study of children from different regions of Georgia. There was a slight slowdown in the rate of biological development of children in areas where the percentage of centenarians is high. Schoolgirls in these areas lag behind their peers from Sukhumi by 1 year and 4 months in terms of puberty (menarche)., from peers from Batumi for 1 year and 9 months., from peers from Tbilisi for 1 year and 10 months. The curves for increasing the body length of boys and girls in coastal areas, which cross at the age of one year later, also differ slightly.

\section{Methods}

Another feature should be taken into account when working with urban and rural children in sports: it is proved that the physical development of children living in rural areas is somewhat lower than that of urban children, especially 6-year-olds. The authors see a possible reason for these differences in different social conditions and low attendance of rural children in pre-school institutions. At the same time, rural children are ahead of their peers in terms of performance.

Thus, the geographical conditions of Georgia have a certain impact on the rate of biological maturation and body type of residents of different regions. The available literature on this issue is very limited. At the same time, such data are necessary for the organization of an effective science-based system of selection and sports orientation of children for athletics.

\section{Conclusion}

The problem of selection in modern conditions of sports development is characterized by a number of socio-economic, organizational, medical and biological aspects. Training highly 
qualified athletes requires high material costs, attracting a large number of qualified coaches and

staff. At the same time, the continuity of children's sports in the country on average is 15$20 \%$, which does not meet the current needs of replenishment of national teams. In this regard, the most important organizational task is to improve the science-based system for selecting prospective athletes in certain regions of the country. Analysis of domestic and foreign literature data on the selection of primary school age for athletics shows that this problem is still far from being solved.

\section{References:}

1. T. I. Alekseeva Geographical environment and human biology. - Moscow: Moscow state University, 1977.;

2. V. S. Smirnova, E. P. Shagurina on the nature of variability and morphological features in men and women in areas with different geographical conditions of habitat, Variability of morphological features in men and women. - M. 1982, pp. 117-132;

3. D. Harre the Doctrine of training-M.; physical Culture and sports, 1971. p. 35-49;

4. J. Harrison Climate adaptation (human Biology) j. Harrison, J. Finer - M., 1973, p. 519-563;

5. Chebotareva, Yu. M. Methods of forecasting sports achievements in the Olympic sports: abstract of thesis Cand. PED. Sciences-Moscow, 1983, $23 \mathrm{p}$

6. V. E. Deryabin on age and geographical variability of the size and type of proportions of longitudinal body sizes in some ethno-territorial groups of the USSR, questions of anthropology., 1980 65, 67-79.;

7. P. K. Kvitsinia Territorial variability of morphological features of men. Questions of anthropology., 1983 72, 79-91 p.

8.N. N. Miklashevskaya., V. S. Solovyov. O. A. Gilyarova, M. Y. Pescina. Growth processes in Abkhazian children and adolescents with a high percentage of centenarians. (Questions of anthropology), 1982g. 13-21 p

9. B. M. Shiyan, V. B. Shpitalny, B. K. Gunyadin, and others. Comparative analysis of physical development and urban children 6-9 years old. Prykarpattia Moscow 1984

10.T. I. Alekseeva Geographical environment and human biology. - Moscow: Moscow state University, 1977;

11. V. S. Smirnova, E. P. Shagurina on the nature of variability and morphological features in men and women in areas with different geographical conditions of habitat, Variability of morphological features in men and women. - M. 1982, pp. 117-132;

12. D. Harre the Doctrine of training-M.; physical Culture and sports, 1971. p. 35-49;

13.J. Harrison Climate adaptation (human Biology) j. Harrison, J. Finer - M., 1973, p. 519-563;

14. Chebotareva, Yu. M. Methods of forecasting sports achievements in the Olympic sports: abstract of thesis Cand. PED. Sciences-Moscow, 1983, 23 p. 
15. V. E. Deryabin on age and geographical variability of the size and type of proportions of longitudinal body sizes in some ethno-territorial groups of the USSR, questions of anthropology., 1980 65, 67-79.;

16. P. K. Kvitsinia Territorial variability of morphological features of men. Questions of anthropology., 1983 72, 79-91 p.

17. N. N. Miklashevskaya., V. S. Solovyov. O. A. Gilyarova, M. Y. Pescina. Growth processes in Abkhazian children and adolescents with a high percentage of centenarians. (Questions of anthropology), 1982g. 13-21 p.

18. B. M. Shiyan, V. B. Shpitalny, B. K. Gunyadin, and others. Comparative analysis of physical development and urban children 6-9 years old. Prykarpattia Moscow 1984

\section{Influence of regional conditions (ethnic, climatic, etc.) of Georgia on the selection methodology and sports orientation Tristan Gulbiani, Merab Maisuradze, Merab Metreveli, Summary}

Identification and selection of motor-gifted children and their correct sports orientation is the most important link in the system of training athletes of international class. the topic reveals the problem of differences in the physiological development of adolescents and their selection for sports.

Key words: selection of children, differences in biological development, climate, morphological differences

\section{Влияние региональных условий (этнических, климатических и др.) Грузии по методике выбора и спортивной ориентации Тристан Гулбиани, Мераб Майсурадзе, Мераб Метревели \\ Резюме}

\footnotetext{
Выявление и отбор дьвигательно одорёных детей и правильная их спортивная ориентация является важнейшим звеном системыподготовки спорртсменов международного класса. В теме раскрывается проблема различий физиологического развития подростков и их отбор для занятияспортом.

Ключевые слова: отбор детей, различия биологического развития, климат, морфологические различия населения и т.д
} 


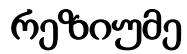

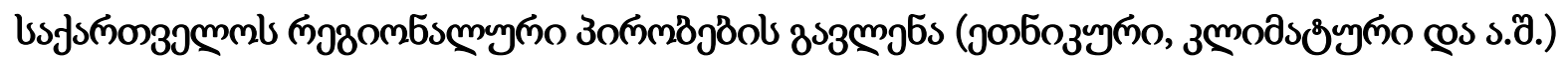

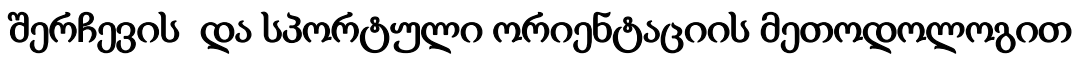

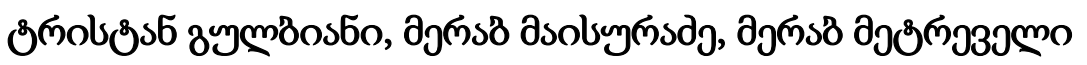

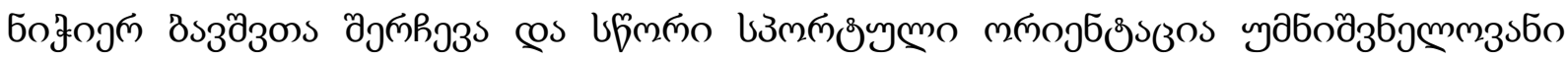

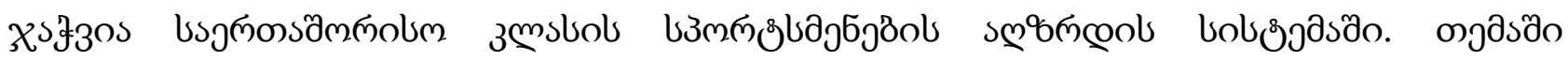

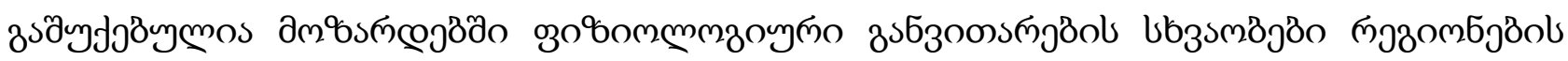

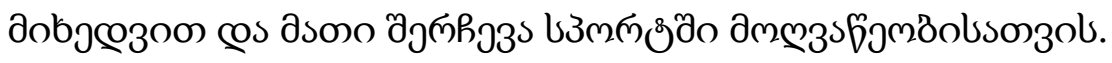

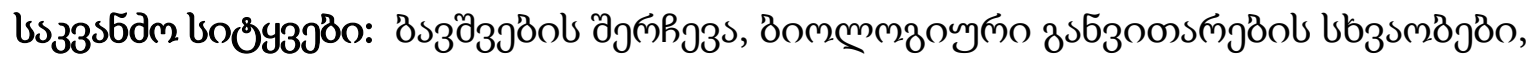

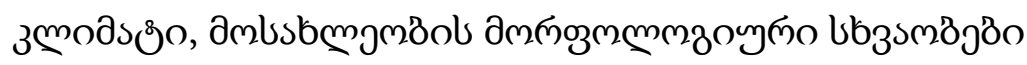

